presence of anti-cN-1A. Anti-cN-1A positivity had a sensitivity of $43.6 \%$ and a specificity of $91.8 \%$ for sIBM. The positive and negative predictive values were $36.4 \%$ and $93.8 \%$, respectively.

There was no significant difference in gender, age at study entry, age at symptom onset, duration of symptoms or max creatine kinase (CK) levels during disease course between the anti-cN-1A positive and negative slBM patients. Dysphagia was present in $19(79 \%)$ of the anti-cN-1A positive and in $17(55 \%)$ of the anti-cN-1A negative sIBM patients $(P=0.06)$.

Conclusion: Antibodies against $\mathrm{cN}-1 \mathrm{~A}$ are the first and so far the only serological marker for sIBM. Our data showed that $\mathrm{cN}-1 \mathrm{~A}$ autoantibodies are specific for sIBM and further corroborate the potential diagnostic role of $\mathrm{cN}-1 \mathrm{~A}$ autoantibodies in this distinct subgroup of myositis.

Disclosure of Interests: Louise Pyndt Diederichsen: None declared, Sine Søndergaard Korsholm: None declared, Line Vinderslev Iversen: None declared, Christoffer Tandrup Nielsen: None declared, Marie-Louise From Hermansen: None declared, Søren Jacobsen: None declared, Nanna Witting: None declared, Markus E. Krogager: None declared, Tina Friis Grant/research support from: Anti cN-1A ELISA kits and EUROLINE Autoimmune Inflammatory Myopathies 16 AG kits have been provided for a project free of charge from Euroimmun.

DOI: 10.1136/annrheumdis-2019-eular.7264

\section{FRI0321 PERFORMANCE OF DIFFERENT PULMONARY HYPERTENSION SCREENING ALGORITHMS IN PATIENTS WITH SYSTEMIC SCLEROSIS PATIENTS}

Mustafa Erdogan ${ }^{1}$, Burcak Kilickiran Avci $^{2}$, Yagmur Ersoy $^{3}$, Cansu Ebren $^{2}$ Zeki Ongen ${ }^{2}$, Gul Ongen ${ }^{4}$, Vedat Hamuryudan ${ }^{1}$, Gulen Hatemi ${ }^{1} .{ }^{1}$ Istanbul University -Cerrahpasa Medical Faculty, Internal Medicine, Division of Rheumatology, Istanbul, Turkey, ${ }^{2}$ Istanbul University -Cerrahpasa Medical Faculty, Department of Cardiology, Istanbul, Turkey, ${ }^{3}$ Istanbul University -Cerrahpasa Medical Faculty, Istanbul, Turkey; ${ }^{4}$ Istanbul University -Cerrahpasa Medical Faculty, Department of Pulmonary Diseases, Istanbul, Turkey

Background: Pulmonary hypertension $(\mathrm{PH})$ is an important cause of morbidity and mortality in patients with systemic sclerosis (SSc). Different screening algorithms have been proposed for identifying patients who have a high probability of $\mathrm{PH}$ and require right heart catheterization $(\mathrm{RHC})$, which is the gold standard for diagnosing $\mathrm{PH}$.

Objectives: To compare the performance of $\mathrm{PH}$ screening algorithms in our patients with SSc.

Methods: Forty-eight consecutive patients, fulfilling ACR/EULAR 2013 SSC criteria, were screened for PH using the, 2015 ESC/ERS, DETECT and ASIG algorithms. Pulmonary function tests (PFT), diffusing capacity of the lung for carbon monoxide (DLCO), trans-thoracic echocardiography, serum NT-proBNP, uric acid assay and high-resolution computed tomography (HRCT) were performed as needed. Patients with known $\mathrm{PH}$, severe interstitial lung disease and severe left ventricular dysfunction were not included. $\mathrm{RHC}$ was performed in all patients with positive screening according to any one of the screening algorithms. Patients with $\mathrm{PH}$ were classified according to the updated $\mathrm{PH}$ classification criteria. Sensitivity and specificity of the 3 screening algorithms were evaluated according to the established cut-off value of $25 \mathrm{mmHg}$ for mean systolic pulmonary artery pressure and for the recently proposed cut-off value of $20 \mathrm{mmHg}$ Results: Among the 48 SSc patients, 15 were excluded due to already diagnosed $\mathrm{PH}(n=4)$, left ventricular dysfunction $(n=4)$, no measurable tricuspid regurgitation velocity (TRV) $(n=5)$ and coexisting lung cancer $(n=2)$. Among the remaining 34 patients, 16 required $\mathrm{RHC}$ according to at least one of the screening algorithms. Demographic and clinical features of remaining 34 patients were summarized in Table 1. Number of patients who had suspected pulmonary hypertension and required $\mathrm{RHC}$ according to ESC/ERS 2015, DETECT and ASIG were 8 (\%25), 9 (\% $27)$, and $13(\% 41)$ respectively (Figure 1). Among the 14 who had RHC, $\mathrm{PH}$ was present in 3 patients according to the 25-mmHg cut-off (Group1 in 1, Group 2 in 1, Group 3 in 1) and in 8 patients according to the 20-mmHg cut-off (Group 1 in 5, Group 2 in 2, Group 3 in 1). The sensitivity and specificity of each algorithm is presented in Table 2. Sensitivity was similar at $100 \%$ for the 3 algorithms, but the ESC/ERS algorithm had better specificity, when $\mathrm{PH}$ was diagnosed with the $25-\mathrm{mmHg}$ cut-off. For the $20-\mathrm{mmHg}$ cut-off, both the sensitivity and the specificity were better with the ESC/ERS algorithm.

Conclusion: The ESC/ERS algorithm seems to have a better performance for detecting $\mathrm{PH}$ in patients with SSc. A limitation of this study was that $\mathrm{RHC}$ was not performed in patients who did not fulfill criteria according to any of the screening algorithms. The sensitivities may be lower than what we propose if there are patients with $\mathrm{PH}$ who are asymptomatic and not captured with any of the algorithms.

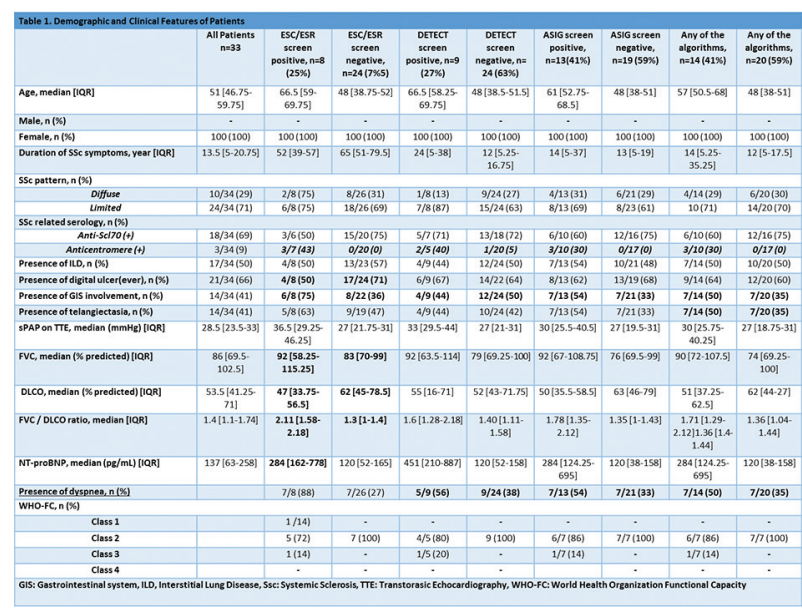

Disclosure of Interests: Mustafa Erdogan: None declared, Burcak Kilickiran Avci: None declared, Yagmur Ersoy: None declared, Cansu Ebren: None declared, Zeki Ongen: None declared, Gul Ongen: None declared Vedat Hamuryudan Consultant for: Abbvie, Amgen, BMS, Jansen, MSD Pfizer, UCB, Speakers bureau: Abbvie, Amgen, BMS, Jansen, MSD Pfizer, UCB, Gulen Hatemi Consultant for: Abbvie, Amgen, BMS, Janssen, MSD, Pfizer, UCB, Speakers bureau: Abbvie, Amgen, BMS, Jansen MSD, Pfizer, UCB,

DOI: 10.1136/annrheumdis-2019-eular.2662

\section{FRI0322 AUTOANTIBODIES PROFILE INFLUENCE ON SYSTEMIC SCLEROSIS INTERSTITIAL LUNG DISEASE. A TERTIARY SPANISH HOSPITAL EXPERIENCE}

Antía García Fernández ${ }^{1}$, Iván del Bosque Granero ${ }^{1}$, Laura Calvo Sanz ${ }^{1}$, Nicolás Almeida Arostegui ${ }^{2}$, Luis Gorospe Sarasúa ${ }^{2}$, Carlos De la Puente Bujidos ${ }^{1}$

${ }^{1}$ Ramón y Cajal University Hospital, Rheumatology, Madrid, Spain; ${ }^{2}$ Ramón y Cajal University Hospital, Radiology, Madrid, Spain

Background: Systemic Sclerosis (SSc) is a rare and heterogeneous connective tissue disease (CTD) characterized by skin fibrosis, vasculopathy/vascular damage and potential visceral impairment. Interstitial lung disease (ILD) constitutes the leading cause of mortality and requires close periodical assessment and follow-up. Diffuse cutaneous sclerosis and specific autoantibody profile (anti SCL70 anti Th/To, Anti U3 RNP and anti PmScl) are considered ILD development risk factors. In contrast, positivity to anticentromere has been considered as a protec tive factor to develop a clinical significant ILD.

Objectives: To assess ILD frequency and severity (extension and func tional impairment) in SSc patients, analyzing the association with the different autoantibodies.

Methods: Retrospective, descriptive study of patients meeting EULAR/ACR 2013 SSc criteria and had a HRTC performed at a tertiary Spanish hospital from 1975 to 2018. One hundred and eight patients were included HRCTs were graded by two radiologists according to Goh et al semiquantitative score. Three groups were established according to the pres ence of different autoantibodies: anticentromere (ACA), antitopoisomerase (ATA), and positivity to other ANAs (nucleolar pattern and other specificities).

Results: Clinical and laboratory characteristics are presented in table 1 . Thirty-three patients had pulmonary involvement, 6 were ACA+, 18 ATA+ and 9 had other ANA specificities. The probability of not having pulmonary involvement among $\mathrm{ACA}+$ and of having pulmonary involvement among ATA + showed statistic significance $(p<0.001$ and $p<0.001)$. Usual intestinal Pneumonia (UIP) was the most frequently reported pattern (6 patients), followed by Non-Specific Interstitial Pneumonia (NSIP 11 patients); Six patients did not meet the radiological criteria for neither UIP or NSIP. No statistical significant difference was found among radio logical pattern and autoantibody profile. Regarding extension: 15 patients 
had non-extensive involvement (ACA: 2, ATA: 7, "other ANAs": 6) performing Goh et al score with the FVC correction. Extensive ILD was found among 18 patients (ACA: 4, ATA: 11, "other ANAs": 3). Despite the fact that ATA+ group was more likely to have an extensive involvement no statistical significance was met. About pulmonary function tests (PFT) the mean FVC was $98,45 \%$ on ACA group, whereas on ATA and other ANAs groups the mean FVC were $88,97 \%$ and $81,43 \%$ respectively. Statistical differences were found between first and third group, However this difference was not found when only patients with pulmonary involvement were analyzed.

Conclusion: In our cohort, ATA and other ANAs groups were more likely to develop pulmonary interstitial disease and to need inmunosuppressant treatment. Although the prevalence of ILD among ACA+ was only $10 \%$, $50 \%$ of them required, due to the functional impairment or extension, inmunosuppressant treatment. In spite of the low ILD-ACA+ incidence this complication should be kept in mind and periodical screening and assessment must be carried out as in other autoantibodies profiles.

Disclosure of Interests: None declared

DOI: 10.1136/annrheumdis-2019-eular.1650

Table 1. ACA ATA Other ANA[1]

\begin{tabular}{|c|c|c|c|}
\hline \multirow[b]{2}{*}{ Table 1} & \\
\hline & ACA & ATA & Other ANA \\
\hline Patients, n (\%) & $60(55,6)$ & $22(20,4)$ & $26(24,1)$ \\
\hline $\begin{array}{c}\text { Sex } \\
\text { Female }(\%) \\
\text { Male }(\%)\end{array}$ & $\begin{array}{c}57(95) \\
3(5)\end{array}$ & $\begin{array}{c}18(81,8) \\
4(18,2)\end{array}$ & $\begin{array}{l}21(80,8) \\
5(19,2)\end{array}$ \\
\hline Age at diagnosis, median (years) & 59 & 55 & 61,5 \\
\hline $\begin{array}{c}\text { Smoke } \\
\text { Active (\%) } \\
\text { Former (\%) }\end{array}$ & $\begin{array}{l}1,7 \\
23,3\end{array}$ & $\begin{array}{l}4,5 \\
4,5\end{array}$ & $\begin{array}{l}11,5 \\
26,9\end{array}$ \\
\hline $\begin{array}{l}\text { DIAGNOSIS } \\
\text { IcSSc (\%) } \\
\text { dcSSc (\%) }\end{array}$ & $\begin{array}{c}55(91,7) \\
4(6,7)\end{array}$ & $\begin{array}{c}4(18,2) \\
17(77,3)\end{array}$ & $\begin{array}{l}11(42,3) \\
11(42,3)\end{array}$ \\
\hline $\begin{array}{l}\text { Time from diagnosis to ILD, } \\
\text { mean (months) }\end{array}$ & 6 & 5 & 0 \\
\hline Death,n (\%) & $8(57,2)$ & $2(14,2)$ & $4(28,6)$ \\
\hline PCR, mean (DS) & $4,69(3,9)$ & $5,25(3,75)$ & $8,08(8,34)$ \\
\hline vSG. median (mm/h) & 18 & 20.5 & 21 \\
\hline $\mathrm{PH}(\%)$ & 23.7 & 18.2 & 19.2 \\
\hline GERD (\%) & 72,9 & 77,3 & 57,7 \\
\hline ILD, n (\%) & $6(10)$ & $18(81,8)$ & $9(34,6)$ \\
\hline FVC, mean (DS) & $98,4(18,5)$ & $88,9(21,7)$ & $81,42(22,8)$ \\
\hline DLCO, mean (DS) & $72,5(20,4)$ & $75,5(35,9)$ & $73,4(20,7)$ \\
\hline
\end{tabular}

\section{FRI0323 EVALUATION OF LIPID PROFILE AND ATHEROSCLEROSIS IN TREATMENT-NAÏVE PATIENTS DIAGNOSED WITH UNDIFFERENTIATED CONNECTIVE TISSUE DISEASE (UCTD)}

Giorgos Papamichail ${ }^{1}$, Athanasios Georgiadis ${ }^{2}$, Theodora Markatseli ${ }^{2}$ Charalampos Milionis ${ }^{1}$, Alexandros Drosos ${ }^{2}$, Paraskevi Voulgari ${ }^{2} .{ }^{1}$ Internal Medicine, University of loannina, Greece, Department of Internal Medicine, Medical School, University of loannina, loannina, Greece; ${ }^{2}$ Rheumatology Clinic, University of loannina, Ioannina, Greece, Department of Internal Medicine, Medical School, University of loannina, Ioannina, Greece

Background: Patients with UCTD cannot be definitely diagnosed with a well-characterized systemic rheumatic disease. These patients often exhibit one of several disease patterns, manifesting multiple nonspecific clinical or serologic abnormalities, sometimes of more than one defined rheumatic disorder.

Objectives: The aim of this study is to investigate lipid profile and atherosclerosis in UCTD patients.

Methods: This is a prospective, observational study which included 30 treatment-naïve UCTD patients. Thirty patients and 30 healthy matchedcontrols were compared for total cholesterol (TC), high-density lipoprotein cholesterol (HDL-c), low-density lipoprotein cholesterol (LDL-C) and triglycerides (TGs). Furthermore, in order to describe endothelial dysfunction and presence of atherosclerosis, we assessed intima-media thickness (IMT) of common carotid artery with the contribution of an experienced sonographer. We also measured Apolipoprotein A1 (ApoA1), Apolipoprotein $B(A p o B)$, Apolipoprotein $E(A p o E)$, Lipoprotein A (LpA), erythrocyte sedimentation rate (ESR), high-sensitivity C-reactive protein (HSCRP) and fibrinogen in the group of patients only.

Results: Thirty UCTD patients were studied. There were 11(36.7\%) men, $19(63.3 \%)$ women and $7(23.3 \%)$ smokers. The mean (SD) age was 54.4
(13.1) years and disease duration was 17.3(10.4) years. All reported Raynaud's phenomenon, 22(73.3\%) had esophagus disorders, $21(70 \%)$ had pulmonary fibrosis and $3(10 \%)$ pulmonary hypertension. Arthritis was present in a great majority of these patients (93\%). The immunological evaluation of the patients showed that $4(13.3 \%)$ had positive anticardiolipin antibodies and $11(36.7 \%)$ had scl-70 (+).

The comparison of IMT between patients and matched-controls revealed an increased IMT in UCTD patients $[0.82(0.32)$ vs $0.6 \quad(0.13) \mathrm{mm}$; $\mathrm{p}<0.001]$. There was also a significant difference in mean (SD) TC [204.4(43.03) in patients vs 238(41.4) in controls; $p$ value<0.004] with respective reduced levels of mean(SD) HDL in patients [50.6(9.5) vs 61.3 (13.3); $p$ value<0.002]. No statistically significant difference was found for LDL-c and TGs.

These patients had mean (SD) ApoA1 146.9(27.6), ApoB 94.9(25.6) ApoE 42.1(10.7), LpA 12.8 (15.9), HSCRP 7.5(13.5), ESR 28.9 (22.6 and fibrinogen 422.9(101.3).

Conclusion: IMT measurement confirmed that UCTD patients are prone to endothelial dysfunction and consequently to atherosclerosis. Treatmentnaive patients had reduced TC levels in combination with low levels of HDL-c reflecting high disease activity. Control of the disease and initiation of specific therapy may induce an improved lipid profile.

Disclosure of Interests: None declared

DOI: 10.1136/annrheumdis-2019-eular.6643

\section{FRI0324 DISEASE ACTIVITY INDICES IN SYSTEMIC SCLEROSIS- WHICH TO USE IN DAILY PRACTICE?}

Laura Groseanu $^{1,2}$, Sorana Petrescu ${ }^{1}$, Andra Balanescu ${ }^{1,2}$, Daniela Opris-

Belinski $^{1,2}$, Violeta Bojinca ${ }^{1,2}$, Florian Berghea ${ }^{1,2}$, loana Saulescu ${ }^{1,2}$,

Sanziana Daia-lliescu ${ }^{1,2}$, Diana Mazilu ${ }^{1,2}$, Andreea Borangiu ${ }^{1,2}$,

Cosmin Constantinescu ${ }^{1,2}$, Maria Magdalena Negru ${ }^{1,2}$, Mihai Abobului ${ }^{1,2}$

Violeta Vlad', Ruxandra lonescu ${ }^{1,2} .{ }^{1}$ Carol Davila University of Medicine and

Pharmacy, Bucharest, Romania; ${ }^{2}$ Sf Maria Clinical Hospital, Bucharest, Romania

Background: Currently there is no fully validated index for assessing overall disease activity in patients with systemic sclerosis (SSc).

Objectives: To estimate the effect of disease activity as measured by 4 disease activity indices on the risk of subsequent organ damage in a EUSTAR center cohort.

Methods: Longitudinal observational study; European Systemic sclerosis study group disease activity index (EScSG DAI), revised EUSTAR disease activity index ( $r$-EUSTAR DAI), 12 point activity index proposed by Minier (12point DAI) were calculated for all patients; the CRISS (The Combined Response Index for Systemic Sclerosis) only for patients included after 2016. Student t-test/Mann-Whitney test, chi-square test were used to evaluate differences across subgroups; Pearson's bivariate correlation/Spearman's rank correlation coefficient to evaluate the association between variables. The predictive value of various variables for major organ involvement was assessed by Roc curves and univariate regression.

Results: 91 patients were selected,77 females (84,61\%), 51,65(13,20) years old at diagnosis, $49,45 \%$ diffuse subset.

Disease activity scores were all higher in male patients and in patients with diffuse cutaneous involvement, digital ulcers(DU), lung fibrosis, scleroderma renal crisis (SRC), arrythmias, muscle atrophy, gastric involvement, antitopoisomerase-1 positive, EscSG DAl correlated with forced vita capacity $(F V C)(r=0.73, p<0.001), \quad \operatorname{DLCO}(r=0.68, p<0.001), \quad \operatorname{DU}(x 2=3.08$ $p=0.05)$, lung fibrosis $(x 2=10.90, p<0.0)$, systolic pulmonary arterial pressure (sPAP) $(r=0.54, p<0.001)$, muscle atrophy $(x 2=11,58, p=0.001)$, diffuse subset $(x 2=11,46, p=0.001)$.

R- EUSTAR DAI correlated with FVC $(r=0.6, p<0.001), \quad \operatorname{DLCO}(r=0,58$ $p<0.001)$, diffuse subset $(x 2=9,52, p<0.01)$, contractures $(x 2=11,23, p=0.001)$, muscle weakness $(x 2=6,61, p=0.01)$, muscle atrophy $(x 2=10,19, p<0.001)$ $\operatorname{SRC}(x 2=4,74, p=0.02)$ and $\operatorname{sPAP}(r=0.5, p<0.001)$.

12 point DAl correlated with $\mathrm{FVC}(r=0.57, \mathrm{p}<0.001), \quad \mathrm{DLCO}(\mathrm{r}=0.66, \mathrm{p}<0.001)$ and $\operatorname{sPAP}(r=0.42, \mathrm{p}<0.001)$.

EscSG predicted well lung fibrosis $(A \cup C=0.79, p<0.001), D U(A \cup C=0.66$, $\mathrm{p}<0.001)$, gastric involvement $(\mathrm{AUC}=0.73, \mathrm{p}<0.01)$ and $\mathrm{SRC}(\mathrm{AUC}=0.9$, $\mathrm{p}=0.01$ ). R-EUSTAR index also lung fibrosis ( $\mathrm{AUC}=0.76, \mathrm{p}<0.001$ ), $\quad \mathrm{DU}$ $(\mathrm{AUC}=0.82, \mathrm{p}<0.01)$ and $\mathrm{SRC}(\mathrm{AUC}=0.84, \mathrm{p}=0.04)$.

12point DAl was a good predictor for lung fibrosis $(A \cup C=0.74, p<0.01)$, DU $(A \cup C=0.78, p=0.05)$, gastric involvement $(A \cup C=0.76, p=0.01)$.

In the regression analysis, lung fibrosis(beta $=0.5,95 \% \mathrm{Cl}=1,21-2,58, \mathrm{p}<0.01$ ) muscle atrophy (beta $=1.49,95 \% \mathrm{Cl}=1.02-2.19, \mathrm{p}=0.03$ ) and rhythm and con duction disturbancies (beta=1.98, $95 \% \mathrm{Cl}=1.31-2.99, \mathrm{p}<0.001$ ) were independent predictors for disease activity evaluated by EScSG. For 12 EUSTAR DAI none of the evaluated parameters proved to independently contribuite to disease activity. For 12point DAl items independently 